\section{The Health of the Industrial Worker in Iraq*}

\section{A. MICHAEL CRITCHLEY}

\section{From the Royal Medical College, Baghdad}

In Iraq an industrial revolution is in full swing and is advancing more quickly than is fully appreciated. Most Iraqi industrialists have learned from the lessons of history and are not committing all the blunders made by the industrialists of the nineteenth century in Europe.

The biggest and most important industry in Iraq is undoubtedly agriculture, and great efforts are now being made to mechanize and to introduce modern methods of irrigation and fertilization. In England agriculture is one of the healthiest occupations but in Iraq it is the reverse. Iraq is divisible into a number of distinct areas according to the nature of the land, and consequently the crops grown in each zone vary so that the health hazards differ likewise, but it is not exaggerating to state that the average agricultural worker (fellah) is a living pathological specimen as he is probably a victim of ankylostomiasis, ascariasis, malaria, bilharzia, trachoma, bejel, and possibly of tuberculosis also. If the various development schemes are allowed to proceed without the advice and wholehearted support and help of the public health specialists and sanitary engineers, such diseases as manmade malaria and bilharzia will spread to areas hitherto free, just as in Egypt.

At the present moment the Iraqi Government Principal Bureau of Statistics is undertaking an industrial survey, and though the results are not available yet, some information can be given. There are approximately 150 firms which employ 50 or more workers, of which the Iraq Petroleum Company is the biggest employer with a pay-roll of over 9,000. In addition, there are many more concerns which employ under 50 persons. Included in the over-50 group of industries are the oil concerns, the weaving and leather manufactures, the brick and cement works, tobacco firms, date packing, cleansing of seeds, and repairs and maintenance of ships. The smaller workshops are extremely varied ranging from the smithies of iron, copper, silver, and gold, to saddle makers, mirror manufacturers, dyers, woolsorters, brush-makers, and tailors.

At present the health authorities do not effectively supervise the workshops, so that child labour is very common. Long hours, including nights, are worked, and frequently the work-places are dirty, badly illuminated, ill ventilated, overcrowded, and equipped with unprotected machinery. The environmental conditions found in some workshops are appalling; for example, in the old tanneries, the copper smithies, the tailors' attics, and the shoemakers' workshops. Naturally the health of the workers in the bad working environment is not satis-

* This paper is based on one delivered to the U.N. Fourth Social Welfare Seminar for Arab States. factory ; bad eyesight, injuries, and illness such as anaemias and tuberculosis are rife, and there is a high incidence of dermatitis.

The dermatological risks in some of the small uncontrolled workshops are well exemplified in the oldfashioned tanneries scattered throughout the country. The contact of the worker's unprotected, bare skin with deleterious solutions is so intimate and prolonged that in spite of the well-known resistance of the dark-skinned to irritants, lesions inevitably develop. Thus in one brief visit to an antiquated tannery in Mosul, I saw more cases of "trade holes" than in 25 years of my professional career. The main lesion is an excoriative, depigmenting and ulcerative dermatitis due to irritation from alkaline solutions used to remove fat from the hides and the subsequent use of chrome. Much less common, but by no means rare, is a malignant pustule contracted mainly by the workers engaged in plucking wool from the sheepskins. In the modern tanneries, which are now replacing the old workshops, these skin hazards are so minimized that dermatitis has become an uncommon occurrence.

A scrutiny of the newer concerns reveals a much rosier position. The biggest employer-the Iraq Petroleum Company-has started off with a health and welfare organization that will bear comparison with that of any other firm in the world. A first-class safety organization has been set up which includes a Safety Committee and a full-time Safety Officer. Therefore, although the presence of hydrogen sulphide in the oil at the main wells at Kirkuk constitutes a risk of the gravest magnitude, yet, owing to the very stringent measures which are being taken to enclose this dangerous oil hermetically from the well-head to the elimination of the gases by burning during the processing of the oil, there are no cases of gas poisoning. Similarly, in the engineering workshops the machines are well sited and guarded, and the shops clean, well-lit, and ventilated. The workers are medically examined before and during employment, are supplied with good canteens, and houses are available for employees of all grades. The sick and injured are cared for in three modern and well-equipped hospitals with 175 beds.

Other Iraqi industrial concerns, e.g., the Iraq Spinning and Weaving Co., the Vegetable Extraction Co., the Bata Shoe Co., have not been slow to follow the good example of the I.P.C. It is of interest to note here that, so far, no cases of byssinosis have been detected amongst the cotton workers employed at the Iraqi Spinning and Weaving Co. This is probably due to two factors : first, length of exposure to cotton dust has not been sufficiently long, and, secondly, this concern being a recent development, the management is employing every modern device to reduce to the minimum the dust in the cardrooms and other parts of the factory. As these firms are situated near large Government hospitals, there is no need for the provision of hospital beds, and the doctors are part-time only, attending for a few hours daily and in emergencies.

Porters are a common, interesting and picturesque feature of Baghdad life, and I investigated a sample group of 100 taken at random from railway yards, 


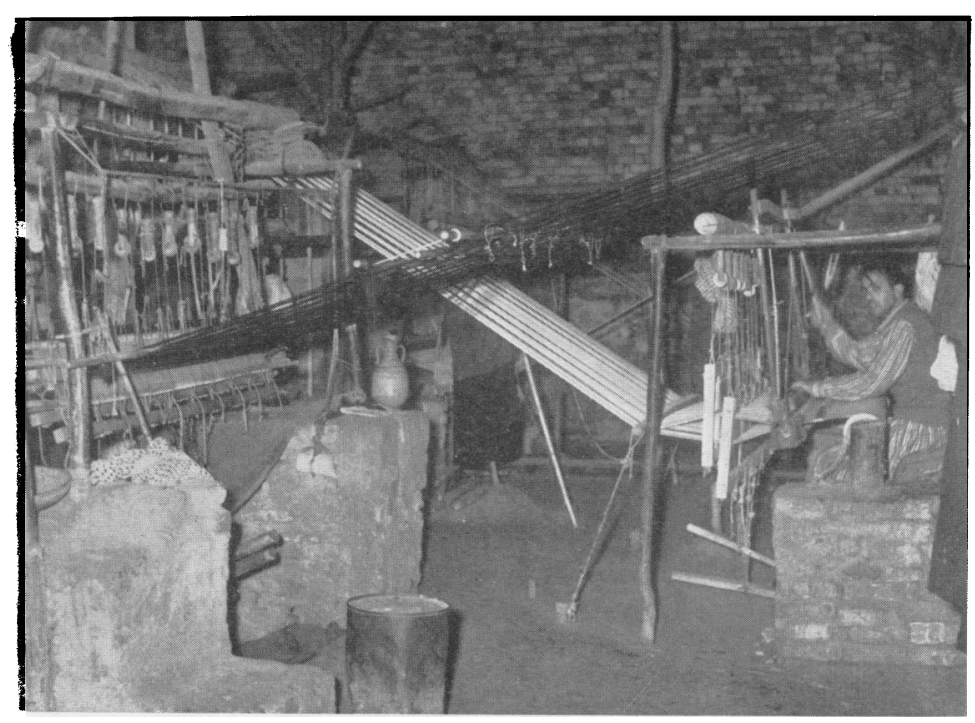

Fig. 1.-Old-fashioned loom, now being replaced by the most modern types.

Fig. 2.-Softening process in a modern tannery.

FIG. 3.-Softening process in an old tannery.

FIG. 4.-Wool sorting.

Fig. 1.

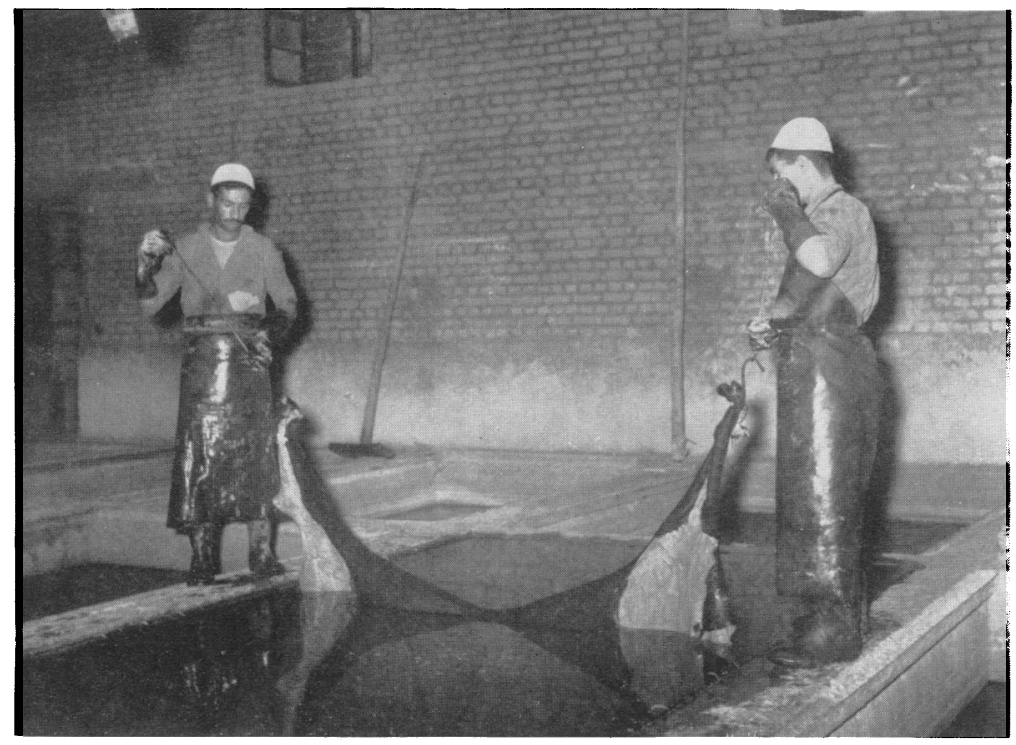

FIG. 2.

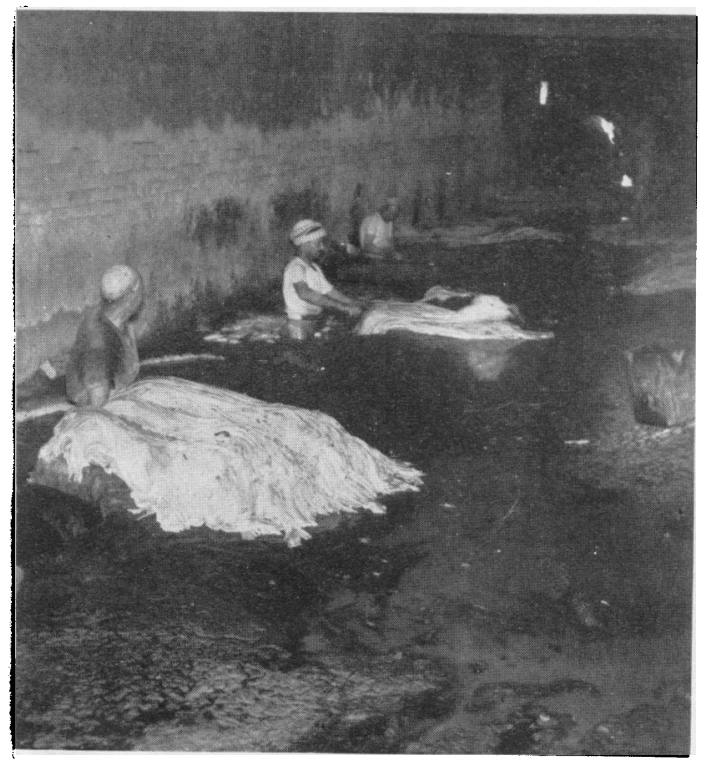

FIG. 3.

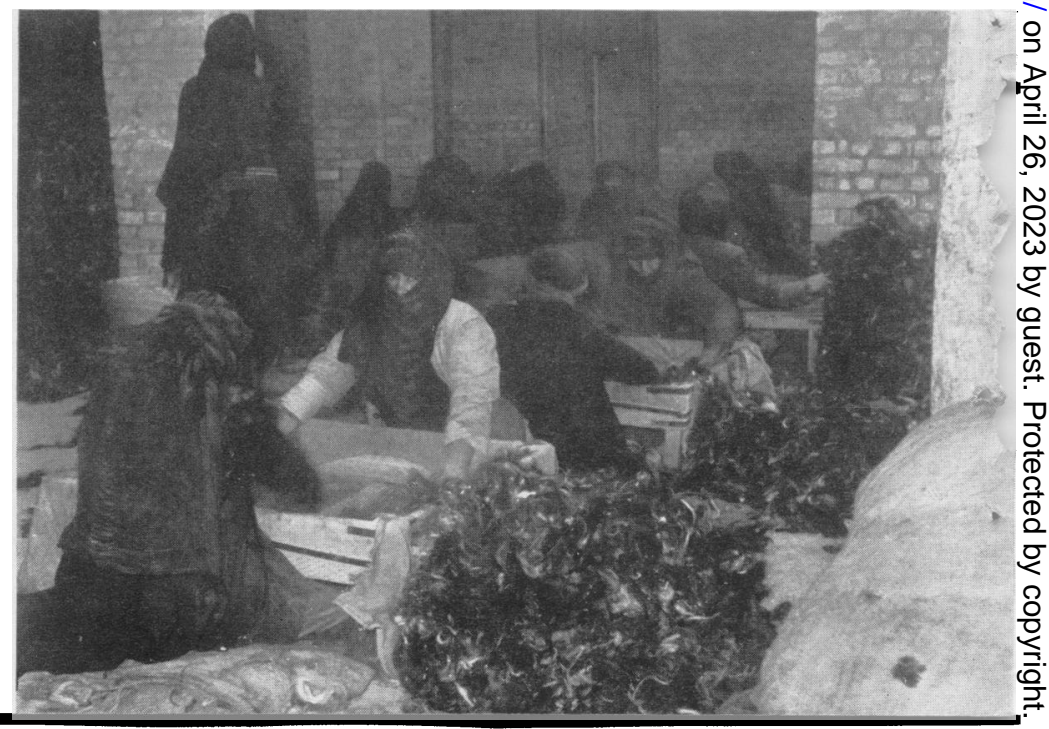


wharves, a factory, and from the heart of the "souk" or bazaar. To understand the existence of this group of workers it is necessary to realize that although, during the past few years since the formation of the Development Board, Baghdad has entered a period of rapid modernization, yet a considerable portion of the business area, especially in the vicinity of the Tigris, remains a district of narrow, tortuous, and uneven passages, low archways opening into Turkish-style courtyards, interspersed with irregular stone steps. Thus this territory is quite unsuited for wheeled traffic and all loads to and from business premises must be carried either by the porters or on the backs of donkeys, mules, or horses.

Over $60 \%$ of the porters examined were not Iraqi, but came from Luristan, a Kurdish district in Iran. Their profession is familial, so that up to 14 years of age $38 \%$ of all porters remain at home employed in agricultural pursuits, then migrate to Baghdad to become porters, remaining so for the rest of their lives. They probably return for a period of a few weeks each year (usually at harvest time) to their families in Persia where they keep their wives if they are married.

In the group reviewed other porters were found to have been at some period of their lives brick workers $(14 \%)$, servants, waiters, soldiers, etc. Each man was asked his age, but it was found that no absolute reliance could be placed upon their replies, for they have a vague conception of time and do not possess birth certificates. Their ages were recorded to range from 14 years (employed as a porter for two years) to 70 years. A youth on starting work begins with loads of approximately $50 \mathrm{~kg}$., but as he gains physique, strength, and skill his loads are increased so that it is found that an adult normally carries weights of $200 \mathrm{~kg}$. ; some have been known to handle over half a ton, being paid extra money for very awkward loads.

The reason for the ability of a porter to handle such enormous loads is that from the start of his work he adopts a method of handling and carrying which is physiologically sound.

Porters examined had been working for periods varying from three months to 50 years, so that it was possible to assess the effects of such an onerous task. The ill effects found were surprisingly few; thus $9 \%$ varicose veins, $4 \%$ arthritis of the spinal column, $6 \%$ hernia, $3 \%$ heart disease. Blood pressure was low (it is commonly low in Iraq) and the highest systolic pressure recorded was 160 and the lowest 90 , with an average of $120 \mathrm{~mm}$. $\mathrm{Hg}$.

Nearly all the workers had a mild keratotic condition of the skin over the iliac crest due to friction of the loads over this site which bears the maximum weight.

It was unusual for the porters to be men of powerful build, and their average weight was $9 \mathrm{st} .10 \mathrm{lb}$. It is customary for the porters to work barefooted, and their feet are broad compared with a European's but singularly free from pes planum and hallux valgus.

Since the foundation of Iraq in 1921, many laws concerning the health and welfare of the working people have been passed, and today a new law has been drawn up with the help of a British adviser which will consolidate and bring up to date the already existing legis- lation. It is known as "The Law concerning Work and Workers" and does not cover agricultural workers. The clauses of this Bill have been compiled in keeping with the spirit of the age, and if carried out efficiently and conscientiously will place Iraq in the ranks of the most socially conscious nations.

(1) No child under the age of 12 years is to be employed and regulations are to be drawn up regarding the employment of young persons. (2) Pregnant women are to be granted three weeks' leave of absence on full pay before the date of their confinement and for three weeks after. (3) Nursing mothers are to be allowed two breaks of half an hour each in order to feed their children. (4) Articles are included to govern hours of work, night work, and overtime. (5) During Ramadan the daily hours are reduced by one. (6) A worker is entitled to annual leave on full pay at the rate of one day for each month worked. (7) Special provisions are set up to deal with claims for compensation, and there are schedules for diseases and rates of compensation. Permission is granted for the list of scheduled diseases to be amended as the occasion arises. (8) The formation of trade unions is legalized, and any employer who p znalizes an employee for joining or not joining a tradeunion is liable to punishment.

So far, the passage of this Bill through Parliament has been fairly smooth, and it is expected that it will be passed without any material alteration.

The subject of industrial health cannot be dismissed without some mention being made of the education of medical students in preventive and social medicine. The course in public health has been considerably modified to bring it more into line with modern concepts. Laboratory investigations into the analyses of water, milk, and food, have been replaced by outside visits and demonstrations, and an elementary course on the industrial diseases likely to be encountered in Iraq is included. As a symbol of this altered outlook, the Department of Public Health in the Royal Medical College is now designated as that of Public Health and Social Medicine.

Finally, a word must be said about the conditions of the handicapped worker. As in other countries of the Middle East the welfare of the disabled has been neglected, so that it is not unusual for such persons to drift into the ranks of the street beggars. There is a great need for this problem to be tackled in a radical manner : first, to introduce measures to prevent disabilities; secondly, to train handicapped persons in suitable employments ; thirdly, to place them in industry, if necessary passing some enactment on the liries of the Disabled Persons Act in England.

\section{Summary}

Health conditions prevailing in the modern factories of Iraq are contrasted with those in the primitive workshops. A short description of the work and health of the porters of Baghdad is included.

My thanks are due to H.E. the Minister of Health, Iraq, for granting permission for publication. 